\title{
Recuperación crítica y devolución sistemática del retorno a la tierra de Orlando Fals Borda
}

\author{
Critical recovery and systematic return \\ of the return to the land of Orlando Fals Borda
}

Normando Suarez*

\begin{abstract}
Resumen
El artículo recorre de manera meticulosa en diversas fuentes primarias, secundarias y terciarias la producción del maestro Fals Borda desde 1953 con su primer trabajo académico "Notas sobre la evolución del vestido campesino en la Colombia central" hasta la última disertación del 28 de marzo del 2008 en Memphis (Tenesse) con motivo de haber recibido el Premio Malinowski. Se centra en un tema crucial: la recuperación crítica y la devolución sistemática, como herramientas claves de la IAP, que puedan aplicarse en el contexto actual de suma importancia para el país: la superación del conflicto y el avance en la construcción de un escenario de postconflicto.
\end{abstract}

Palabras clave: acuerdos de paz, devolución sistemática, escenario de postconflicto, IAP, recuperación crítica.

\begin{abstract}
The article meticulously reviews various primary, secondary and tertiary sources of the production of the master Fals Borda since 1953. It begins with his first academic work "Notes on the evolution of peasant dress in Central Colombia" until the last dissertation on March 28, 2008, in Memphis (Tennessee) on receiving the Malinowski Prize. The award was on a crucial issue: critical recovery and systematic return, as key tools of the IAP. This can be applied in the current context of great importance for the country: the overcoming of the conflict and the development in the construction of a post-conflict scenario.
\end{abstract}

Keywords: critical recovery, IAP, peace agreements, post-conflict scenario, systematic return.

\section{(c) $($ ) $\circledast(2)$}

ReCibido: I5 DE JULIO DE 2019 | ApRobAdo: I6 DE OCTUBRE DE 2019

Cómo CITAR ESTE ARTICULO

Suarez, N. (2020). Recuperación crítica y devolución sistemática del retorno a la tierra de Orlando Fals Borda. Collectivus, Revista de Ciencias Sociales, 7 (1),11-24. DOI: https://doi.org/10.15648/Collectivus.vol7num1.2020.2528

* Magíster en Administración Pública de la Escuela superior de Administración Pública. Universidad Nacional de Colombia Sede Bogotá. Departamento de Sociología. Bogotá, Colombia. sunorma1@hotmail.com 


\section{Introducción}

A propósito de la coyuntura actual de Colombia en un complejo y difícil proceso de posconflicto, es oportuno y pertinente formular algunas preguntas relacionadas con los aportes de Orlando Fals Borda, quien después de 83 años de vida de compromiso permanente con la paz (Fals Borda, 2004, 2007a, 2008c) murió con la angustia de la continuidad (Fals Borda, 2008b) el 10 de agosto de 2008. Dichas preguntas se hace oportuno formularlas, en primer lugar para superar los factores estructurales de la violencia bicentenaria del país y en segundo lugar porque a lo largo de su vida, el maestro Fals Borda fue consecuente con la construcción de la Investigación Acción Participativa - IAP y el Paradigma Alternativo Holístico (Fals Borda, 2008b), a partir del acumulado derivado de lo que llamó progresivamente en 1960 la Investigación Telética (Fals Borda, 2008c), en 1977 la Investigación Activa (Fals Borda, 1977a), en 1997 la Investigación Participativa (Fals Borda, 1998) en procura de la democratización y la reconciliación de los pueblos: ¿Cuál es el significado y alcance de su obra para avanzar desde los territorios en la construcción de la paz? ¿Es útil y eficaz la IAP para avanzar en la reconciliación de colombianos y colombianas?

A una década de la muerte del maestro mayor OFB: ¿Cuál es la viabilidad política y factibilidad comunitaria para la aplicación de la IAP recontextualizada y reformulada en perspectiva de la implementación del Acuerdo de Paz colombiano? ¿Las celebraciones de recordación con motivo de los diez años del fallecimiento de OFB son respuestas a su mayor frustración (Fals Borda, 2004) como sociólogo y como ser humano para superar la violencia "extraña a mi terruño natal" y "volver por los senderos de paz" (Fals Borda, 2007b) de su costa caribe y su "Arenosa" (Barranquilla) donde nació, vivió su juventud y retornó siempre? ¿Los homenajes por su partida confirman la paradoja del aforismo "lo más conocido es lo menos reconocido" (Hegel, 1968) y niegan la profecía autocumplida (Merton, 2002), en relación con la respuesta en término de reconocimientos y tributo de sus paisanos y paisanas a su legado para la paz, su comprometida vida y vigente obra?

\section{Recuperación crítica y devolución sistemática de la i(a)p}

El trayecto de vida del sentipensante OFB se puede comprender de manera integral en los dos momentos de la IAP: la recuperación crítica de la memoria cultural de las comunidades y la necesaria devolución sistemática del saber adquirido superando las tensiones de la praxis (teoría/práctica, sujeto/objeto y objetividad/compromiso) (Fals Borda, 2007b).

Retorno a la tierra de OFB hace una década en clave de IAP se plantea en la Colombia de ese momento como devolución sistemática con recuperación crítica para la superación del conflicto y avance en la construcción de un escenario de postconflicto.

El primer momento de la indagación para todas las investigaciones realizadas por OFB se encuentra en las fuentes de información primarias, secundarias y terciaria recuperadas desde 1953 en su primer trabajo académico "Notas sobre la evolución del vestido campesino en la Colombia central" (Fals Borda, 1953), hasta su última disertación en versión sintética expuesta el 28 marzo de 2008 para recibir el Premio Malinowski en Memphis - cinco meses antes de su muerte Tennesse (Fals Borda, 2008c). Se incluyen en este inventario de manera destacada por su rigor las fuentes de información originales de la Monografía sociológica de la vereda de Saucío - "Campesinos de los Andes" (1953) e "Historia doble de la Costa" (Fals Borda, 1981, 1984, 1986a; Guzman, Fals Borda, \& Umaña Luna, 1962), así como las correspondientes a por lo menos 150 investigaciones. 
Los soportes documentales básicos de esas investigaciones se encuentran en primer lugar en el Archivo de Investigadores de la Universidad Nacional de Colombia (Fals Borda, 2004). En segundo lugar, en el Centro Documental Regional Orlando Fals Borda del Banco de la República en Montería y en tercer lugar, el Fondo documental registrado a su memoria OFB en la vereda de Saucío -Municipio de Chocontá (Cundinamarca).

En las seis antologías (Borja M, Pineda, \& Viscaino, 2009; Fals Borda, 2009; Herrera \& López, 2012; Jaramillo, 2010; Suárez, 2017; Universidad Nacional, 2009) publicadas hasta la fecha de las cuales existe registro se puede tener una aproximación de las devoluciones identificadas por compiladores del método de exposición de los procesos de investigación del intenso periplo vital falsbordiano/ de OFB desde 1948 con la composición "Cantata a la Paz" hasta su "Mensaje a la Junta de Acción Comunal de la vereda de Saucío" a donde volvió por última vez en junio 10 de 2008.

En la antología Orlando Fals Borda: una vida de compromiso social (Borja M et al., 2009), el valor agregado más importante de esta publicación es una relación exhaustiva de la prolífica pluma de Orlando Fals Borda desde 1953 hasta 2005 (ob. Cit).

El anterior inventario hay que completarlo con una compilación "Hacia el socialismo raizal y otros escritos" (Fals Borda, 2007a), en la cual se exponen quince escritos que abarcan el período 2003 - 2007 agrupados en cinco capítulos temáticos: Socialismo raizal y democracia radical; Orden, territorio y político; Globalización y segunda República; Sociología y sociedad y Vivencias regionales (ob. Cit).

La última antología publicada en el 2017 (Suárez, 2017), rescata y destaca, además de “Campesinos de los Andes," diez escritos que recorren el alfa y el omega de la producción falsbordiana más significativa y sentida: la reforma agraria, acción comunal, la violencia en Colombia, la Investigación Acción Participante (IAP), la sociología, la región Caribe, el ideario de Camilo Torres, la relación universidad-sociedad y los dos últimos documentos elaborados por Orlando Fals Borda, que contienen disertaciones expuestas al momento de recibir sendos premios internacionales: La investigación acción en convergencias disciplinarias (Fals Borda, 2007b) y Problemas contemporáneos en la aplicación de la sociología al trabajar en la Investigación Acción Participativa (Fals Borda, 2008a), inicialmente titulada Continuidad y disidencia entre científicos activistas.

En la obra falsbordiana de OFB la recuperación crítica como momento primero de la naciente IAP se descubre en la investigación publicada en 1962 con el título "La violencia en Colombia" cuando reconoce las limitaciones de las teorías sociológicas con las cuales fue formado en Estados Unidos para analizar la confrontación bipartidista nacional como un problema de patología social (Guzman et al., 1962; Serrano, 2015; Sicerone, 2015). A partir de ese momento hace la ruptura epistemológica con los modelos estructuralfuncionalistas de las ciencias sociales para explicar causalmente las violencias recurrentes en la historia colombiana. En el 2007 concluye que la violencia política ancestral fue la partera demoníaca de la IAP que llegó a su clímax en el "bogotazo" de 1948 (Fals Borda, 2017).

Se puede verificar la aplicación progresiva de la recuperación crítica en los trabajos y ponencias realizados por OFB presentados, analizados y valorados en los doce eventos internacionales dedicados a IAP. Especialmente, en los dos encuentros mundiales realizados en Cartagena hace cuarenta y veinte años respectivamente.

En desarrollo de la declaración de principios consensuada en el Congreso Internacional de Cartagena (Fals Borda, 1977b), Fals Borda abandona la concepción estructural funcionalista del cambio institucional controlado, utilizado en la investigación Campesinos de los Andes, y hace la transición a construir y asumir la Investigación Acción Participante (IAP), con todas sus consecuencias teóricas y prácticas (Fals Borda, 1977a). 
Una de las cinco bases de la incipiente IAP declarada hace cuarenta y dos años (1977) fue: "La construcción de técnicas que faciliten la búsqueda de conocimiento en forma colectiva, la recuperación crítica de la historia y de las culturas de los pueblos originarios y otros grupos, así como la devolución sistemática del conocimiento adquirido" (Fals Borda, 2006). Hace veinte y dos años (1997) se complementó el anterior binomio con una de las trece pautas de la investigación participativa: "Por la fluidez natural de los fenómenos sociales, culturales, económicos y políticos, estos hay que verlos como procesos históricos sujetos a análisis hermenéuticos" (Fals Borda, 1998).

En el marco de la incipiente Investigación Acción Participativa, Orlando Fals Borda trata de superar los estudios de caso, realizando un trabajo de alcance regional (Capitalismo, hacienda y poblamiento en la Costa Atlántica - 1973) (Fals Borda, 1976b); luego avanza con una investigación de orden nacional (Historia de la cuestión agraria (Fals Borda, 1976a) y retorna, nuevamente, a una de carácter regional: Historia doble de la Costa (Fals Borda, 1979, 1981). El autor de esos trabajos, se propuso hacer una presentación más comprensiva de la vida, de las luchas campesinas y de la formación social del norte del país. En esta última investigación aplicó los resultados de otros trabajos previos como: Revoluciones inconclusas en América Latina (Fals Borda, 1980b); Influencia del vecindario pobre colonial en las relaciones de producción de la Costa Atlántica Colombiana (Fals Borda, 1977a); La ciencia y el pueblo: nuevas reflexiones sobre la investigaciónacción (Fals Borda, 1980a); Ciencia propia y colonialismo intelectual (Fals Borda, 1970); Subversión y cambio social (Fals Borda, 1986b).

La puesta a prueba de la emergente metodología con sus dos fases (recuperación-devolución) la vivenció Orlando Fals Borda adelantando la prolongada investigación (Fals Borda, 1979, 1986a) con los campesinos del occidente del Caribe continental colombiano, a partir de las comunidades de la zona rural de MompoxLoba, Atlántico y Bolívar, Cuenca del río San Jorge entre Sucre y Córdoba contenida en los cuatro tomos de Historia doble de la Costa (Fals Borda, 1979, 1986a).

La recuperación crítica básica de Mompox y Loba,(volumen I), el Presidente Nieto (volumen II), La resistencia en el San Jorge (volumen III) y Retorno a la tierra (volumen IV) están en los 2258 documentos que OFB recolectó y utilizó para hacer devolución sistemática en "Historia doble de la Costa", material que "Comprende libros raros y antiguos periódicos regionales, grabaciones, fotografías, objetos y cuadros de valor histórico, mis diarios de campo, manuscritos y notas de archivos nacionales y extranjeros, en los que basé para la confección del trabajo" (Fals Borda, 2002), y luego, como archivo personal los donó hace treinta años (1988) al área cultural del Banco de la República en Montería para constituir el hoy Centro de Documentación Regional que lleva su nombre. Antes las críticas por defectos de la documentación de “Historia doble de la costa, OFB responde que ante "el cuasi-silencio de los historiógrafos, [...] estas fuentes han podido y pueden seguirse consultando en bibliotecas o en las carpetas y otros elementos colocados en el Centro Regional de Documentación para el servicio público" (Ob. Cit., p.xvii).

Para la reconstrucción crítica de la historia y de las culturas de los pueblos originarios del caribe colombiano, OFB aplica a los más de dos mil doscientos soportes documentales las técnicas de la Investigación Acción Participativa, la cual estaba en formación en aquellos momentos. El nuevo camino para la acción combina la información sobre hechos con la reflexión y la comunicación basadas en observaciones sucesivas que denomina imputación (Fals Borda, 1980a, 1986b).

También recurre a la ilación de eventos, apoyada en la reconstrucción de situaciones con documentos antiguos de notaría y archivos oficiales, búsqueda en archivos de baúl, entrevistas con ancianos informantes, proyección ideológica, análisis de fuentes secundarias publicadas, documentación fotográfica, recolección de escritos de intelectuales locales, observación dirigida, participación activa y alguna experimentación 
social, en vista de la posible inexistencia de fuentes decantadas sobre la estructura social de la región costeña (Chalarca, 2019; Rappaport, 2018) Colombia in collaboration with the Asociación Nacional de Usuarios Campesinos (anuc.

En los cuatros volúmenes que constituyen la serie del caribe occidental profundo, la devolución sistemática de la investigación acción en referencia se expone con "advertencias" metodológicas que se reiteran en cada tomo en cuanto su concepción, exposición y presentación en dos estilos o canales diferentes de comunicación.

$\gg$ Canal [A]: “Por las páginas de la izquierda corren el relato, la descripción, el ambiente, la anécdota”. Los críticos de Historia doble plantean como problemático el uso y papel de la imaginación en la construcción de la obra por este conducto.

$\gg$ Canal [B]: Por las páginas de la derecha corren simultáneamente la interpretación teórica respectiva, los conceptos, las fuentes y la metodología de aquello que contiene el canal A y, también, resúmenes de relatos )(Fals Borda, 1986a). Los contradictores de los cuatro libros señalan una ideologización de este canal vulnerando el principio de neutralidad axiológica o valorativa y generando una tensión entre el científico y el político: ciencia neutra o comprometida?

En principio Fals Borda recomienda que para recuperar lo que se devuelve en cada volumen, la lectura de cada canal puede hacerse de corrido independientemente, desde el principio hasta el final del libro. Pero advierte, "la experiencia seguida por los lectores de los tomos anteriores indica que es más productivo y pedagógico leer cada capítulo completo de una canal, seguido de la lectura de su contraparte del otro canal, y sin saltar de uno a otro en las llamadas [A], [B], [C], o [D]. Estas se han hecho con el fin técnico de llamar la atención sobre unos temas centrales que requieren apoyo teórico y documentación, ejercicio que pueden adelantar los especialistas"'.

Desde otra perspectiva y marco de referencia se puede hacer la lectura de la obra asumiendo que el canal A es el texto y el canal B el contexto.

Los diez años del "retorno a la tierra" de OFB, están asociados en doble sentido al título y contenido del cuarto volumen de Historia doble de la Costa. La estructura de Retorno a la tierra es el primer caso de la aplicación de la IAP construida por OFB a partir de lo sistematizado en el primer Simposio Mundial Investigación Activa en Cartagena de Indias en 1977.

En armónicos sonidos estereofónico del porro palitiao "María Barilla" ${ }^{3}$ y combinando los diversos colores, saberes y sabores que matizan y trascienden la realidad territorial del trópico costeño, OFB a partir del canal A hace recuperación crítica del punto 1: De retorno a la madre tierra. El relato \# 2: La amachada conquista del Sinú. La descripción \# 3: El congregador de pueblos. El Contexto en el \# 4: En las sabanas: entre ricos y explotados. El ambiente en el \# 5: Los embrujos del Sinú. El tema 6: Primeros vientos de organización. El conflicto del numeral 7: El turno de los violentos. La respuesta en el \# 8: El destello de la ANUC y la conclusión de la praxis en el punto 9: Reconstruyendo los hormigueros (Fals Borda, 1986a).

1 "Advertencias" antes de iniciar los capítulos de los cuatros tomos de Historia doble de la costa.

2 En el primer tomo "Mompox y Loba" de la primera edición 1979 se advierte en la página 13 "la lectura de cada canal puede hacerse independientemente, de corrido, aunque resultara más completa la información si se leen ambos canales coordinadamente. Para efecto se han colocado llamadas [A], [B], [c] o [D] en cada capítulo del canal A (izquierda) que corresponden a explicaciones específicas identificadas con las mismas letras, en el canal B (derecha)".

3 En 1887 nació en Ciénaga de Oro la gran bailadora y prodigio de la raza cósmica triétnica de María de los Ángeles Tapia, María Barilla, como lavandera profesional fue miembro de la Sociedad de Obreras Redención de la Mujer. Hoy el folclor popular le rinde homenaje con un porro viejo palitiao bautizado con su nombre que es "himno" del departamento de Córdoba. 
De forma concurrente y complementaria, por el canal B de Retorno a la Tierra se hace devolución sistemática del conocimiento adquirido en el canal A y se puede contrastar en la coyuntura actual colombiana con los puntos pactados en el Acuerdo para la Paz (2016) (Presidencia de la República de Colombia., 2017a).

En el primer punto del canal (B), OFB recupera el ethos de los campesinos de la subregión del Bolívar grande identificado en la monografía de la vereda de Saucío - Campesinos de los Andes (1955) (Fals-Borda, 1961) que tiene su correlato con el retorno a la madre tierra del canal A. El segundo numeral "Machismo y colonización" se puede relacionar con lo pactado en el Acuerdo de Paz en lo referente al anexo de género (Ob. Cit). El tercer ítem "Reordenando el agro", cuarto "En las sabanas: entre ricos y explotados", el quinto "Riqueza agrícola y explotación humana" y el sexto "Socialismo y campesinismo" se puede contrastar y encontrar coincidencias y diferencias con el primer punto del pacto de agosto y noviembre 2016 por un nuevo campo colombiano: Reforma Rural Integral (Ob. Cit).

En el séptimo capítulo analiza con nuevos conceptos, método, fuentes y relatos "El turno de los violentos" a partir de la investigación de "La violencia en Colombia" (Guzman et al., 1962) y su reedición en 2005 con dos tesis centrales de total actualidad en la Colombia de hoy (Fals Borda, 2006). La primera, interpreta a la llamada "violencia" como el resultado de una política destructiva del entorno y del tejido social, diseñada e impulsada conscientemente por una oligarquía que se ha querido perpetuar en el poder a toda costa, desatando el terror y la guerra. La segunda tesis sostiene que este proceso de patología social se viene repitiendo en ciclos más o menos acompasados, en los que se cambia el nombre del actor violento, directo o inspirador, por el del nuevo actor.

Bell Lemus, en la presentación de Historia doble de la costa (Fals Borda, 2002), esgrime que, la devolución sistemática en los cuatro tomos de Historia doble de la Costa no ha estado exenta de la polémica por el contenido del canal B; lo exageradamente académico; la falta de rigor, especialmente en el uso de las fuentes; la controversia por el papel asignado a la imaginación en la elaboración de la obra; excesivo simplismo en tratamiento de ciertos temas y otros han criticado la manifiesta voluntad del autor de escribir un texto políticamente comprometido (p.xiv). Como autor principal de esta obra colectiva, OFB responde y aclara los que a su juicio son los problemas planteados de la recuperación crítica de la historia y cultura de los pueblos caribeño (Ob. Cit., p. xii).

En cuanto a correcciones y complementos de datos, Fals B reconoce siete errores en las fechas de acontecimientos en ambos canales ( $\mathrm{A}$ y B). Lo relacionado con discusiones sobre asuntos tratados en la obra, opiniones sobre estilos, metodología e ideologías señala que "debo seguir dejándolo, naturalmente, en las manos de los pensadores y escritores independientes." Valora las observaciones de novelistas, historiadores y escritores. Relaciona y reconoce las organizaciones e investigadores que se ocuparon de llenar con sus aportes las lagunas de la investigación (Ob. Cit., pp. xviii-xix). Ante la crítica principal de los canales utilizados para exponer la obra, OFB en una nota de autor responde con todo el énfasis del caso:

Quiero insistir en la defensa del uso declarado de la imaginación y la ideología en las pesquisas científicas -lo que aconsejó y ejecutó hasta el respetado Einstein-, como aparece en los canales A y B de la Historia. Debo recordar que, en caso de la imaginación, se trató de elaboraciones de "corteza", o marginales, dentro del marcos culturales e históricos definidos, cuyos elementos tomé como "núcleos", es decir, como 'datos columnas' debidamente confirmados. El registro formal de estos datos y en notas de pie de páginas se encuentra en el Canal B. Por razones de comunicación y estilo, consideré adecuado compartir la alegría que sentía en aquellos momentos de reflexión y redacción, que dramatizaban rasgos personales o gestas colectivas de lo que estaba descubriendo en el terreno o en los documentos.

En cuanto a la ideología, cuando escribí la Historia doble, el inolvidable maestro Gerardo Molina, dirigente político e intelectual de la mayor dimensión, ya me había matriculado como socialista humanista...En ello no hizo sino constatar viejas preocupaciones colectivas como las tenemos muchos científicos - - que preferimos la democracia a las dictaduras y la participación al monopolio. Por eso tomé parte en la temprana articulación de la Investigación-Acción Participativa (IAP), escuela en la que se inscribe mi obra". (Fals Borda, 2002, p.5) 


\section{OFB: Diez años de retorno a la tierra y la devolución de la paz desde los territorios}

En el 2004 y ocho años después de publicado Retorno a la Tierra (IV tomo), OFB hace una retrospectiva de la violencia en la costa atlántica trayendo al presente la devolución comparada de la dolorosa experiencia de la llamada violencia en Colombia. En el caso de la confrontación armada en la región del Caribe colombiano, territorio considerado no azotado en principio con la fuerza de la violencia andina en la década de los cincuenta hasta los sesentas, el caribeño Fals Borda demuestra cómo fue afectado progresivamente por la mantis (maríapalito) del conflicto a partir de la lucha por la tierra del campesinado costeño y la resistencia encarnada en la Asociación Nacional de Usuarios Campesinos ANUC línea Sincelejo (Fals Borda, 1984, 1986b). Su comprensión del problema de violencia en su tierra de nacimiento la expresa considerando que el Caribe continental colombiano era reconocido como un remanso de paz para preguntarse: "¿qué había pasado en mi tierra desde 1948?" (Fals Borda, 2004, 2007b, 2008c). Supone que hubo un primer fatal descuido de la clase dominante por la suerte del campo, que era fuente de su riqueza y poder: "no sintieron la urgencia de la transformación por la justicia, dejando a las clases trabajadoras al arbitrio de la ley de la fuerza y de la explotación capitalista más salvaje" (Ob. Cit., p.131).

Entonces, esta ley brutal se aplicó con cierta facilidad por agentes externos comprometidos con la violencia de interior del país, en la que también cayeron los dirigentes costeños. Con su vivencia señala que:

Sangre inocente y campesina fue cubriendo poco a poco veredas y playones, y fue subiendo hacia los Montes de María, por un lado, y por el otro por las ciénagas de mis primos, los hombres hicoteas de San Martín de Loba y Magangué, y por los rastros de mis abuelas chimilas de Mompox y de Pijiño. (Ob. Cit., p.131)

Manifiesta que la mancha sangrienta hizo metástasis en el tejido social regional y se fue extendiendo más al norte sin que los dirigentes costeños actuaran para atajarla, hasta alcanzar los fabulosos paraísos del Cesar y del Ariguaní, y subió secando los 56 ríos de la Sierra Nevada de Santa Marta, hasta casi saturar con el terror la ancestral cultura del humor y del dejar hacer.

En este punto del testimonio hace alusión a los cuatro volúmenes escrito de Historia doble de la Costa: “Insistí entonces, con colegas de los Andes, en el análisis del trágico fenómeno de la Violencia política. Aquel libro de 1962 causó mucho ruido, pero los culpables lograron sepultarlo. Al menos por un tiempo. Las danzas macabras de la destrucción y el sectarismo continuaron. Volví sobre el asunto en la "Historia Doble", destacando en cada tomo el valor de antihéreos caribeños no violentos como Juan José Nieto y Francisco Serpa. Revaloré la resistencia civil local y exalté al San Jorge macondiano con su santoral popular. Todo resultó muy corto para paliar la tragedia desata, que culminó en las peores masacres de la historia de Colombia, en plácidos lugares como Macayepo, Ovejas y San Onofre" (Ob. Cit., p.131).

Infiere, sin embargo, aquella violencia extraña al terruño natal empezó a ser endógena. La geohistórica región Caribe está así dejando de ser costeña. "Estamos sucumbiendo a la violencia foránea y a la delincuencia resultante".

El asesinato del sociólogo Alfredo Correa De Andrei (2004), entre otras, lo impulsó a Fals Borda a escribir, en un especial estado de angustia, “De poco han servido 'Mensajes' musicales, libros, revistas, sermones y discursos. Tampoco leyes, decretos y bravatas de gobernantes" (Ob. Cit., p.132).

Lapidariamente termina el mensaje haciendo un desesperado llamado:

Por eso, mis paisanos, colegas y amigos, esta es mi mayor frustración como sociólogo y como ser humano. Pasé casi toda mi vida en guerras múltiples, a veces deformadas, por el narcotráfico o sufriendo sus trágicas consecuencias, tratando de entenderlas y explicarlas, combatiendo el belicismo con ideas, propuestas y algo de malicia indígena. Pero ya no tengo tiempo, en mi vejez, de seguir campaneando sobre la Violencia o por la Segunda República, apenas esbozarlas, como es mi actual preocupación. (Ob. Cit., p.132) 
El anterior planteamiento de la violencia en el norte de Colombia a 2004 es posible asociarlo en una relación de causa efecto con lo expuesto en la devolución sistemática de los cuatro volúmenes de "Historia doble de la Costa" y con lo pactado en 2016 entre el Gobierno Nacional y las FARC. En particular, cuanto el conflicto genera afectaciones a las poblaciones más vulnerable. Los puntos 4, 6, 8 y 9 del canal A y 4, 5, 8 y 9 del canal B de Retorno a la tierra (IV tomo) tiene convergencias con el punto cinco del Acuerdo de Paz: las víctimas del conflicto que las identifica en los siguientes términos:

\begin{abstract}
La terminación de la confrontación armada significará, en primer lugar, el fin del enorme sufrimiento que ha causado el conflicto. Son millones los colombianos y colombianas víctimas de desplazamiento forzado, cientos de miles los muertos, decenas de miles los desaparecidos de toda índole, sin olvidar el amplio número de poblaciones que han sido afectadas de una u otra manera a lo largo y ancho del territorio, incluyendo mujeres, niños, niñas y adolescentes, comunidades campesinas, indígenas, afrocolombianas, negras, palenqueras, raizales y rom, partidos políticos, movimientos sociales y sindicales, gremios económicos, entre otros. No queremos que haya una víctima más en Colombia. (Presidencia de la República de Colombia., 2017a, p.4)
\end{abstract}

Se agrega al anterior inventario, las Universidades que como la del Atlántico, Cesar, Córdoba y Magdalena han sido protagonistas de desarrollo regional, pero también víctima del conflicto. Fals Borda ya había recomendado volver los ojos, respetar y reaprender de los cuatro pueblos que han conformado la esencia de la nación colombiana, que son también víctimas del conflicto armado y a los que hay que reparar. Son ellos: los indígenas, los negros de palenques, los artesanos y campesinos antiseñoriales y los patriarcas colonos de la frontera agrícola. De estos se deben recuperar valores sociales fundantes, de presencia reconstructiva y universal: La solidaridad, la libertad, la dignidad y la autonomía (Fals Borda, 2007a)

Es reiterativo en la necesidad de recuperar las raíces de los pueblos originarios y sus valores dominantes para tener una mayor comprensión de las realidades y problemas territoriales actuales y para los propósitos de la indispensable reconstrucción social que demanda la paz colombiana. En relación con las universidades de la región caribe, además de ser damnificadas de la confrontación (Universidades del Atlántico, Cesar, Córdoba y Magdalena) a las que hay que reparar simbólica y materialmente como institución de educación superior, el educador popular Fals Borda considera que ellas deben contribuir a responder a los tres retos de la IAP en un escenario de posacuerdo.

Primero, la construcción de un paradigma alterno, estudiando los grupos originarios de víctimas, destacando sus valores de reconciliación y solidaridad humana. Segundo, entender y combinar, en el contexto regional, las complejidades de las sociedades en posconflicto: la memoria, lo oral, lo particular, lo local. Tercero, los métodos para resistir la homogeneización de la globalización para defender las identidades y la vida como naciones y pueblos autónomos (Fals Borda, 2006).

Reconoce que en estas ha habido un proceso de cooptación participativa, ya que son para el 2006 por lo menos 2500 universidades de 61 países y 32 escuelas regionales, en las que se enseña o practica la Investigación Acción Participativa. Pero advierte que los intentos de llevar a la práctica estos trabajos con profesores y estudiantes se han dificultado por la inflexibilidad de los pensum, los ritmos-en semestres o años- de la enseñanza y la exigencia de tesis individuales para optar títulos ${ }^{4}$.

La propuesta del octavo punto del canal B: "Reforma agraria y ciencia social" del IV tomo de Historia doble de la Costa reinterpreta teóricamente la alternativa de solución al conflicto del campo colombiano formulada y ejecutada mediante la ley 135 de 1961 con los resultados de la tesis doctoral de OFB "La tierra y el hombre en Boyacá" (Fals Borda, 1957) reescrita en edición tercera del año 1979.

4 Como se analizó en el Simposio Mundial Investigación Activa y Análisis Científico, realizado en Cartagena en el año de 1977, estos trabajos son de mediano y largo plazo y requieren de una continuidad mínima, con persistencia y compromiso personal o de equipos, por lo menos por parte de profesores y alumnos que mantengan el pulso de los trabajos más allá de cualquier semestralización. 
En el anterior sentido, debe ser tema de estudio con la IAP las propuestas de la Reforma Rural Integral pactada en el primer punto del Acuerdo de Paz (Presidencia de la República de Colombia, 2017, pp.10-12). Particularmente, la formulación e implementación de los cuatro Programas de Desarrollo con Enfoque Territorial - PDET y los respectivos planes de transformación subnacionales -PATR de la región Caribe (Decreto Ley $\left.\mathrm{N}^{\circ} 893,2017\right)^{5}$, así como los otros doce PDET subregionales en los territorios nacionales en donde ha sido más intenso el conflicto por la tierra tomando como universo los 170 municipios más afectados por la violencia en Colombia.

El retorno a la tierra de OFB en retrospectiva debe contribuir a implementar el punto 9 del IV tomo (Fals Borda, 1986, pp.194-223): la reconstrucción de los hormigueros aplicando la IAP reformulada en el marco del Paradigma Holístico Alternativo y recontextualizada a partir del enfoque territorial, género, étnico y del principio de sostenibilidad ambiental contenido en el Acuerdo para la Paz (Presidencia de la República de Colombia, 2017, pp.10-12).

Independiente de cualquier juicio de valor acerca de la tragedia nacional de los últimos setenta años, para la superación del conflicto interno y avanzar en la consolidación de la paz en Colombia es necesario la construcción de mecanismos para la democratización del conocimiento y la reconciliación de colombianos y colombianas. Por sus demostrados resultados, la Investigación Acción Participativa- IAP se constituye en el principal instrumento para la implementación de los seis puntos del Acuerdo Final Gobierno -FARC.

La anterior hipótesis se validará en un escenario del posconflicto colombiano si se recupera críticamente la praxis y propuestas aportadas por Orlando Fals Borda con su método participativo en convergencias disciplinarias (Fals Borda, 2007, pp.389-400) y se hace devolución sistemática de las acciones colectivas para superar las causas de la violencia en Colombia; se consolida la reforma agraria integral, se concreta el enfoque territorial, de género y étnico del Acuerdo final para la Paz; se garantiza la participación de las poblaciones más vulnerables para la superación de la confrontación, y se asegurar la reparación de las víctimas (con especial énfasis de los pueblos originarios) a través de acciones afirmativas de verdad, justicia, reparación y no repetición (Presidencia de la República de Colombia, 2017, pp.10-12).

Complementariamente, la ejecución del posacuerdo demanda un alto componente de educación para la paz territorial. La IAP falsbordiana a través del diálogo de saberes es garantía para la sostenibilidad en la implementación de lo pactado entre los diferentes actores e instituciones locales y nacionales. En devolución sistemática se proponen en concreto los siguientes instrumentos, métodos y paradigma del comprometido Fals para la implementación y verificación de cada uno de los seis puntos del Acuerdo de Paz en Colombia y sus territorios:

$\leadsto$ Punto 1: Para la Reforma Rural Integral del nuevo campo colombiano los resultados adaptados de la reforma agraria diseñada y agenciada desde el Ministerio de Agricultura y la Facultad de Sociología de la Universidad Nacional por Orlando Fals Borda a partir de investigaciones como "La Tierra y el hombre en Boyacá", la "Violencia en Colombia", "Historia doble de la Costa" y sus últimos escritos del 2007 y 2008 (Presidencia de la República de Colombia., 2017a). Retomar las propuestas de ordenamiento territorial falsbordiano (Fals Borda, 2007a) para los Programas de Desarrollo con Enfoque Territorial -PDET y Planes de Acción de Transformación Regional- PATR. Partir de los planteamientos de los pueblos originarios para la reconstrucción de los planes de vida de indígenas, afrocolombianos, raizales y colonos utilizando la IAP. Asumir la praxis redefinida de la Juntas de

5 Los cuatros PDET en la Región caribe; (42 municipios, 8 departamentos) son los siguientes: (Montes de María (15 municipios, 2 departamentos), Sur de Córdoba (7 municipios, 1 Departamento), Sur de Bolívar (7 municipios, 2 departamentos) y Sierra Nevada-Serranía del Perijá (15 municipios, 3 departamentos). 
Acción Comunal (Fals Borda, 1960) como formas de organización del campo colombiano no solo de los Espacios Territoriales de Capacitación y Reintegración ETCR sino de toda la nueva ruralidad del país.

» Punto 2: Para la participación política apropiar en su integralidad la Investigación Acción Participativa -IAP como método que potencia la recuperación crítica y devolución sistemática de abajo hacia arriba de los saberes para la democratización del conocimiento y la reconciliación de las comunidades desde los territorios en conflicto(Fals Borda, 2007a, 2008c).

$\Rightarrow$ Punto 3: Para el fin del conflicto, la adaptación, adopción e implementación de todos los instrumentos aportados por Orlando Fals Borda identificados en los dos puntos anteriores, especialmente, para la reincorporación socio-política de los promotores/as comunitarios de Paz y Convivencia no solo de los espacios territoriales de capacitación sino de sus áreas de influencia (Fals Borda, 2004, 2007a, 2008c).

$\leadsto$ Punto 4: Para la solución al problema de las drogas ilícitas adaptar, adoptar e implementar la IAP para la construcción participativa y desarrollo de los planes Integrales comunitarios y municipales de Sustitución y Desarrollo Alternativo (PISDA), el programa Nacional Integral de Sustitución de Cultivos de Uso llícito (PNIS) integrado a la Reforma Rural Integral y el programa de prevención del Consumo y Salud Pública (Fals Borda, 2007a).

$\Rightarrow$ Punto 5: El Acuerdo sobre las Víctima del conflicto pactó un Sistema Integral de Verdad, Justicia, Reparación y No Repetición. Para cada uno de los cuatro momentos de la Justicia Especial para la Paz se sugiere específicamente (Ob. Cit.):

- 5.1. El aporte de la obra de OFB se puede materializar en cuanto a la Verdad histórica utilizando de la IAP la recuperación crítica de la memoria con los actores del conflicto a partir de la respectiva Comisión de la Verdad, la Convivencia y la No Repetición, así como la devolución de la verdad reconstruida a las víctimas del conflicto (Ob. Cit.).

- 5.2. La Justicia Especial para la Paz puede incorporar instrumentos de indagación e imputación de la IAP para cumplir su misión e identificar los métodos pedagógicos participativos utilizables en la comprensión de la justicia transicional por parte de las víctimas del conflicto y sus organizaciones (Ob. Cit.).

- 5.3. Para la reparación a víctimas en términos de reconocimientos de responsabilidades colectivas, reparaciones colectivas, la atención psicosocial, el desplazamiento y retorno, la restitución de la tierra y el fortalecimiento a la política de reparación a víctimas se propone apropiar y asumir todo el instrumental de la IAP indicada en los puntos 1, 2, 3 y 4 a fin de concertar una estrategia de fortalecimiento de los planes nacionales de reparación colectiva.

- 5.4. Para las Garantías de No Repetición se propone adaptar, adoptar e implementar la devolución sistemática de la IAP falsbordiana para asegurar la promoción de una cultura del respeto de los derechos humanos, la protección de los derechos humanos y el fortalecimiento de los mecanismos de la labor que desempeñan los defensores de DDHH y sus organizaciones.

$\leadsto$ Punto 6: Son mecanismos de implementación y verificación del Acuerdo de Paz: la Comisión de Seguimiento, Impulso y Verificación (CSIVI); el Plan Marco de Implementación; el Sistema Integrado de información y medidas de transparencia; la priorización de la implementación normativa; el capítulo étnico; el componente Internacional de Verificación de la CSIVI - El Acompañamiento Internacional en la implementación y la Pedagogía, difusión y comunicación de los Acuerdos. En estos ocho mecanismos la IAP en el marco de Paradigma Holístico Alternativo y los otros métodos y técnicas complementarios de la misma se constituye en instrumento fundamental para la concreción del 
Pacto de Paz territorial (Fals Borda, 2008c).

Con la apropiación de la IAP se operacionalizan los anteriores mecanismos para la ejecución completa y sistemática de los 558 compromisos (Instituto Kroc de Estudios Internacionales de Paz, 2019), observables y medibles a través de indicadores e índices del Acuerdo que requieren acciones prácticas susceptibles de seguimiento, evaluación y control por parte de todos los actores que tienen arte y parte en la implementación del Acuerdo Final para la Paz. Además, se superan las tensiones estratégicas de otros sistemas, métodos y herramientas para la verificación de la implementación de los 74 subtemas y 18 temas del Acuerdo (Presidencia de la República de Colombia., 2017a). De otra parte, se asegura la sostenibilidad del proceso y legitimidad del mismo que son los principales desafíos del pacto por la reconciliación, convivencia y el derecho a la paz.

Una medida razonable de cuanta recuperación crítica se ha generado en estos cuatro década derivada de la aplicación de las metodologías participativas para el estudio del conflicto interno asociado con fenómenos de violencia sería el balance que verificara el aporte de la obra de OFB para aclimatar la paz en otros contexto en conflicto y responda la pregunta: ¿Cuántas investigaciones se han realizado a nivel regional, nacional, en el ámbito latinoamericano, del gran caribe como el internacional con devolución sistemática del conocimiento generado a partir de la IAP que hayan facilitado casos exitosos de procesos de reconciliación, postconflicto y paz, y de esta forma poder confirmar la validez y eficacia del aporte de la comprometida obra falsbordiana para la superación del conflicto colombiano.

Es el mejor homenaje al legado de Orlando Fals Borda en sus diez años de fallecido como se puede confirmar en sus propias palabras:

\begin{abstract}
El esfuerzo de reconstruir nuestra sociedad y el ethos de tolerancia y paz queda ahora en las manos y en los corazones de las nuevas juveniles generaciones y antiélites que veo más apta, liberadas, informadas e imaginativas que la mía. Las guerras, la intolerancia, la estulticia gobernante deben terminar en esas buenas manos. Según mis orígenes presbiterianos de la Arenosa (Barranquilla), parece que tendré licencia de seguimiento de estos reclamos y de la contradictoria vida terrenal, desde el sitio del otro mundo que el hado me asigne. Tengan la seguridad, de que me seguiré examinando con los demás para que los colombianos lleguemos por fin a ganar la paz con justicia, y dignidad, prosperidad general, que nos merecemos por lo menos desde la misteriosa llegada de Bochica a estos trópicos. No sigamos siendo los "dejaos" del paseo de la historia. (Fals Borda, 2004, p.133; 2008, p.10)
\end{abstract}

El retorno a la madre tierra de las cenizas de OFB hace una década después de deambular cinco años por diferentes lugares ${ }^{6}$, nos debe interpelar en primera persona ante la crítica coyuntura actual colombiana y comprometernos a superar el reto del conflicto interno. Consecuentemente, disponernos a consolidar el postconflicto recuperando y utilizando todos los instrumentos reformulados y recontextualizados de la IAP y el Paradigma Holístico Alternativo para avanzar en la democratización del conocimiento, la reconciliación, la construcción y la devolución de la paz desde los territorios colombianos. Es el mejor y justo homenaje a su coherente vida y vigente obra.

\title{
4. Conclusiones
}

El anterior recorrido que hemos hecho de la obra de Orlando Fals Borda nos permite concluir en primer lugar, que se hace necesario recuperar su paradigma holístico alternativo como una excelente oportunidad para consolidar los Acuerdos de Paz firmados por el Gobierno colombiano con las FARC. Con la apropiación de la IAP se pueden operacionalizar los anteriores mecanismos para la ejecución completa y sistemática de los 558 compromisos (Instituto Kroc de Estudios Internacionales de Paz, 2019) observables y medibles a

$6 \quad$ Las cenizas de Orlando Fals Borda fueron depositadas el 19 de junio de 2014 en el mausoleo frente a la Capilla de la Sede Bogotá de la Universidad Nacional de Colombia. 
través de indicadores e índices del Acuerdo que requieren acciones prácticas susceptibles de seguimiento, evaluación y control por parte de todos los actores que tienen arte y parte en la implementación del Acuerdo Final para la Paz. Además, se superan las tensiones estratégicas de otros sistemas, métodos y herramientas para la verificación de la implementación de los 74 subtemas y 18 temas del Acuerdo. De otra parte, se asegura la sostenibilidad del proceso y legitimidad del mismo que son los principales desafíos del pacto por la reconciliación, convivencia y el derecho a la paz.

El balance presentado, nos indica que una medida razonable de cuanta recuperación crítica se ha generado en estas cuatro década derivada de la aplicación de las metodologías participativas para el estudio del conflicto interno asociado con fenómenos de violencia, sería el balance que verificara el aporte de la obra de OFB para aclimatar la paz en otros contexto en conflicto y responda la pregunta: ¿Cuántas investigaciones se han realizado a nivel regional, nacional, en el ámbito latinoamericano, del gran caribe como el internacional con devolución sistemática del conocimiento generado a partir de la IAP que hayan facilitado casos exitosos de procesos de reconciliación, postconflicto y paz, y de esta forma poder confirmar la validez y eficacia del aporte de la comprometida obra falsbordiana para la superación del conflicto colombiano?.

Nos motiva a plantear este interrogante, como un reto permanente por parte de los sociólogos pertenecientes a las nuevas generaciones, ya que podemos concluir que será sin duda el mejor homenaje al legado de Orlando Fals Borda en sus diez años de fallecido como se puede confirmar en sus propias palabras: "El esfuerzo de reconstruir nuestra sociedad y el ethos de tolerancia y paz queda ahora en las manos y en los corazones de la nuevas juveniles generaciones y antiélites que veo más apta, liberadas, informadas e imaginativas que la mía. Las guerras, la intolerancia, la estulticia gobernante, debe terminar en esas buenas manos. Según mis orígenes presbiterianos de la Arenosa (Barranquilla), parece que tendré licencia de seguimiento de estos reclamos y de la contradictoria vida terrenal, desde el sitio del otro mundo que el hado me asigne. Tengan la seguridad, de que me seguiré examinando con los demás para que los colombianos lleguemos por fin a ganar la paz con justicia, y dignidad, prosperidad general, que nos merecemos por lo menos desde la misteriosa llegada de Bochica a estos trópicos. No sigamos siendo los "dejaos" del paseo de la historia" (Fals Borda, 2007a).

El retorno a la madre tierra de las cenizas de OFB hace una década después de deambular cinco años por diferentes lugares, nos debe interpelar en primera persona ante la crítica coyuntura actual colombiana y comprometernos a superar el reto del conflicto interno. Consecuentemente, disponernos a consolidar el postconflicto recuperando y utilizando todos los instrumentos reformulados y recontextualizados de la IAP y el Paradigma Holístico Alternativo para avanzar en la democratización del conocimiento, la reconciliación, la construcción y la devolución de la paz desde los territorios colombianos. Es el mejor y justo homenaje a su coherente vida y vigente obra.

\section{Referencias bibliográficas}

Borja M, O., Pineda, J., \& Viscaino, M. (2009). Una vida de compromiso social.Orlando Fals Borda. Bogota: Escuela Superior de Administración Pública-ESAP.

Chalarca, U. (2019). Historia gráfica de la lucha por la tierra en la Costa Atlántica. Bogota: La Silueta.

Decreto Ley N 893. Diario Oficial de la República de Colombia, Bogotá, Colombia, 28 de mayo de 2017. 
Fals-Borda, O. (1961). Campesinos de los Andes; estudio sociológico de Saucío. ([1. ed. ca). Bogotá,: Universidad Nacional,.

Fals Borda, O. (1953). Reseña de revistas. Revista Colombiana de Folklore, (2), 139-147.

Fals Borda, O. (1957). El hombre y la tierra en Boyacá. Bases sociohistóricas para una reforma agraria. Bogota: Ediciones Documentos Colombianos.

Fals Borda, O. (1960). Monografías sociológicas No. 4 Acción Comunal en una vereda colombiana: su aplicación sus resultados y su interpretación. Bogota: Universidad Nacional.

Fals Borda, O. (1970). Ciencia propia y colonialismo intelectual. Mexico: Editorial Nuestro Tiempo.

Fals Borda, O. (1976a). Capitalismo, hacienda y poblamiento en la Costa Atlántica. Bogota: Punta de Lanza.

Fals Borda, O. (1976b). Historia de la cuestión agraria en Colombia. Bogota: Punta de Lanza.

Fals Borda, O. (1977a). El agro en el desarrollo histórico colombiano. Ensayos de Economía Política. Bogota: Punta de Lanza.

Fals Borda, O. (1977b). Memoria Simposio mundial Investigación Activa y Análisis Científico de Cartagena. Critica y Política En Ciencias Sociales. Bogota, Colombia: Punta de Lanza, Universidad de los Andes.

Fals Borda, O. (1979). Historia doble de la Costa. Tomo I Mompox y Loba. Bogota, Colombia: Carlos Valencia Editores.

Fals Borda, O. (1980a). La sociología en Colombia: balance y perspectivas. III Congreso de Sociología. Bogota: Asociación Colombiana de Sociología.

Fals Borda, O. (1980b). Revoluciones inconclusas en América Latina. Mexico: Siglo XXI.

Fals Borda, O. (1981). El Presidente Nieto. Tomo II. Bogota, Colombia: Carlos Valencia Editores.

Fals Borda, O. (1984). Resistencia en el San Jorge. Tomo III. Bogota, Colombia: Carlos Valencia Editores.

Fals Borda, O. (1986a). Reterno a la Tierra. Tomo IV. Bogota, Colombia: Carlos Valencia Editores.

Fals Borda, O. (1986b). Subversión y Cambio Social ( $2^{\circ}$ ed.). Bogota: Universidad Nacional de Colombia Tercer Mundo.

Fals Borda, O. (1998). Participación popular: retos del futuro. Compilación y análisis. ICFES-IEPRI-Colciencias.

Fals Borda, O. (2002). Historia doble de la Costa. Bogota: Universidad Nacional de Colombia- Banco de la República- El Áncora Editores.

Fals Borda, O. (2004). En defensa de la costeñidad y la paz Caribe: mi gran frustración. El Heraldo.

Fals Borda, O. (2006). Situación contemporánea de la IAP y vertientes afines. Ponencia presentada para el 1er Encuentro Internacional de Investigadores en Acción.

Fals Borda, O. (2007a). Hacia el socialismo raizal y otros escritos. Bogota: Edicione Desde abajo y CEPA.

Fals Borda, O. (2007b). La investigación en convergencias disciplinarias. Montreal. Latín American Studies Association LASA. 
Fals Borda, O. (2008a). Continuidad y disidencia entre científicos activistas. Los problemas contemporáneos en la aplicación de la sociología al trabajar en la Investigación Acción Participativa. Memphis. Tennessee: Sociedad de Antropología Aplicada - Premio Malinowski (Mimeógrafo).

Fals Borda, O. (2008b). La subversión en Colombia: El cambio social en la historia. FICA-CEPA.

Fals Borda, O. (2008c). Me queda la angustia de la continuidad. Revista Foro, (50), 108-112.

Fals Borda, O. (2009). Una sociología sentipensante para América Latina. Bogota: Siglo del Hombre Editores y CLACSO.

Fals Borda, O. (2017a) La Investigación Acción en convergencias disciplinarias (Montreal, Canadá: Asociación de Estudios Latinoamericanos - LASA Conferencia Conmemorativa OXFAM América Martín Diskin, 8 de septiembre de 2007. En Campesinos de los Andes y otros escritos antológicos /OFB. Primera edición. Bogotá: Universidad Nacional de Colombia.

Fals Borda, O. (2017b). Campesinos de los Andes y otros escritos antológicos /OFB. Primera edición. Bogotá: Universidad Nacional de Colombia - Editor Normando Suárez.

Guzman, G., Fals Borda, O., \& Umaña Luna, E. (1962). La violencia en Colombia: Estudio de un proceso social (Tomo I). Bogota: Ediciones Tercer Mundo.

Hegel, G. W. F. (1968). Ciencia de la Lógica. Paris: Hachette/Solar.

Herrera, N., \& López, L. (2012). Ciencia, compromiso y cambio social. Buenos Aires: El Colectivo- Lanzas y Letras-Extensión Libros.

Instituto Kroc de Estudios Internacionales de Paz. (2019). Tercer Informe Sobre La Implementación Del Acuerdo De Paz. s.d.

Jaramillo, E. (2010). Antología de Orlando Fals Borda. Madrid: Agencia Española de Cooperación Internacional para el Desarrollo.

Merton, R. K. (2002). Teoría y estructura social. FCE.

Presidencia de la República de Colombia. (2017a). Acuerdo Final para la terminación del conflicto y la construcción de una paz estable y duradera.

Rappaport, J. (2018). Visuality and writing as action: Participatory Action Research on the colombian Caribbean Coast. Revista Colombiana de Sociologia, 41(1), 133-156. https://doi.org/10.15446/rcs.v41n1.66272

Serrano, Y. (2015). El Estado en Cuba. Reflexiones en torno a su encargo social en relación con las familias. Collectivus, Revista de Ciencia Sociales, 2(2), 74-100. https://doi.org/10.15648/coll.2.2015.5

Sicerone, D. (2015). El marxismo des-colonizado como detracción a la crítica de Popper al historicismo. Collectivus, Revista de Ciencia Sociales, 2(2), 134-160. https://doi.org/10.15648/coll.2.2015.7

Suárez, N. (2017). Cronología de Orlando Fals Borda 1925-2017. En Campesinos de los Andes y otros escritos antológicos /OFB. Primera edición. Universidad Nacional de Colombia, 409-417.

Universidad Nacional, C. (2009). Antología Orlando Fals Borda. Bogota: Universidad Nacional de Colombia. 